\title{
New Perspectives in the Treatment of Colorectal Metastases
}

\author{
Dominique Elias $^{a} \quad$ Luca Viganò $^{b}$ Franco Orsic ${ }^{c}$ Marta Scorsettid \\ Tiziana Comito $^{d}$ Jan Lerut ${ }^{\mathrm{e}}$ Davide Cosola ${ }^{\mathrm{b}}$ Guido Torzillib \\ aDepartment of Surgical Oncology, Gustave Roussy, Cancer Campus, Grand Paris, France, bepart- \\ ment of Surgery, Division of Hepatobiliary and General Surgery, Humanitas Clinical and Research \\ Center, Humanitas University, Rozzano, 'Department of Interventional Radiology, European Institute \\ of Oncology, Milan, dDepartment of Radiotherapy, Humanitas Clinical and Research Center, Humani- \\ tas University, Rozzano, Italy, e Department of Abdominal and Transplantation Surgery, Cliniques \\ Universitaires St-Luc, Université Catholique de Louvain, Brussels, Belgium
}

\section{Key Words}

Colorectal liver metastases and peritoneal carcinomatosis · Liver transplantation .

Radioembolization - Radiofrequency ablation and microwave ablation .

Stereotactic body radiation therapy

\begin{abstract}
Background: In recent years, the management of metastatic colorectal cancer has become more aggressive and more multidisciplinary. New treatment options have been proposed in addition to the standard approach of resection of liver metastases and chemotherapy.

Summary: Selected patients with synchronous limited peritoneal and liver disease (peritoneal cancer index $<12$ and $<3$ liver metastases) can be scheduled for aggressive treatment, including cytoreductive surgery, hyperthermic intraperitoneal chemotherapy, and liver resection. This approach has achieved survival benefits, even if the treatment is unlikely to be curative in most patients. Moreover, liver transplantation has been recently reconsidered for liver-only metastases, resulting in the de facto reinstatement of the chance of surgery for some unresectable patients. Even though indications for liver transplantation remain to be standardized, preliminary studies have reported extremely promising outcomes. Radioembolization has proven to be an effective additional tool for the treatment of unresectable tumors, and its potential role in association with chemotherapy for resectable disease
\end{abstract}

Elias and Viganò contributed equally to the manuscript as the first authors. 
is currently being investigated. Stereotactic body radiation therapy is a safe, non-invasive, and effective therapeutic option for patients with inoperable oligometastatic disease. Thanks to recent technical progress, high radiation doses can now be delivered in fewer fractions with excellent local disease control and a low risk of radiation-induced liver injury. Finally, radiofrequency ablation (RFA) for colorectal metastases has become more effective, with results approaching those of surgical series. New interstitial treatments, such as microwave ablation and irreversible electroporation, could overcome some of the limitations of RFA, thereby further expanding indications and optimizing outcomes. Key Messages: Currently, a multidisciplinary approach to patients with colorectal liver metastases is mandatory. Aggressive surgical treatments should be integrated with all the available non-surgical options to maximize disease control and patient survival.

Copyright (C) 2016 S. Karger AG, Basel

\section{Introduction}

Over recent decades, liver surgery for colorectal liver metastases (CLM) has evolved markedly. After preliminary reports in the 1980s, surgery became the standard of care at the end of the 20th century and is now performed whenever possible, provided that complete resection is achievable [1-4]. Even patients with multiple bilobar nodules or synchronous extrahepatic disease are commonly considered for resection [5-8]. Excellent results in terms of safety (mortality risk $<2 \%$ ) and efficacy (5-year actual survival rates of about $50 \%$ ) have strongly encouraged these broader indications [9-12]. At the same time, modern chemotherapy regimens and new targeted therapies have contributed to improved survival for metastatic colorectal cancer patients [13-15]. This favorable scenario led clinicians to adopt an aggressive multidisciplinary approach to CLM, including non-surgical treatments, to maximize disease control and patient survival.

New perspectives have recently opened up in the treatment of CLM. These involve the possibility of curative treatment of limited synchronous peritoneal metastases, the proposal of radioembolization, new considerations concerning liver transplantation (LT) and stereotactic body radiation therapy (SBRT), and progress in interstitial minimally invasive treatments. These five new perspectives are successively discussed in this article.

\section{Peritoneal Carcinomatosis (PC): Still a Contraindication to Hepatectomy?}

Recent studies have clearly demonstrated that limited PC can be effectively treated with cytoreductive surgery (CRS) plus hyperthermic intraperitoneal chemotherapy (HIPEC) $[16,17]$. The 5-year overall survival after surgery for PC is similar to that after surgery for CLM [18]. These results led to further consideration as to whether limited PC associated with CLM is a definitive contraindication to hepatectomy. The Gustave Roussy group designed a case-control study to assess the long-term prognosis of patients with PC of colorectal origin and synchronous CLM after surgical treatment with curative intent, including complete CRS, intraperitoneal chemotherapy, and CLM resection [19]. From a prospectively maintained database, all patients with PC of a colorectal origin and synchronous CLM who were undergoing potentially curative treatment between 1993 and 2009 were manually matched to all suitable patients with isolated PC treated in the same period. The authors adopted the following matching criteria: age, peritoneal cancer index (PCI), site of the primary colorectal cancer (colon/rectum), lymph node status of the primary tumor $(\mathrm{pN})$, and postopera- 


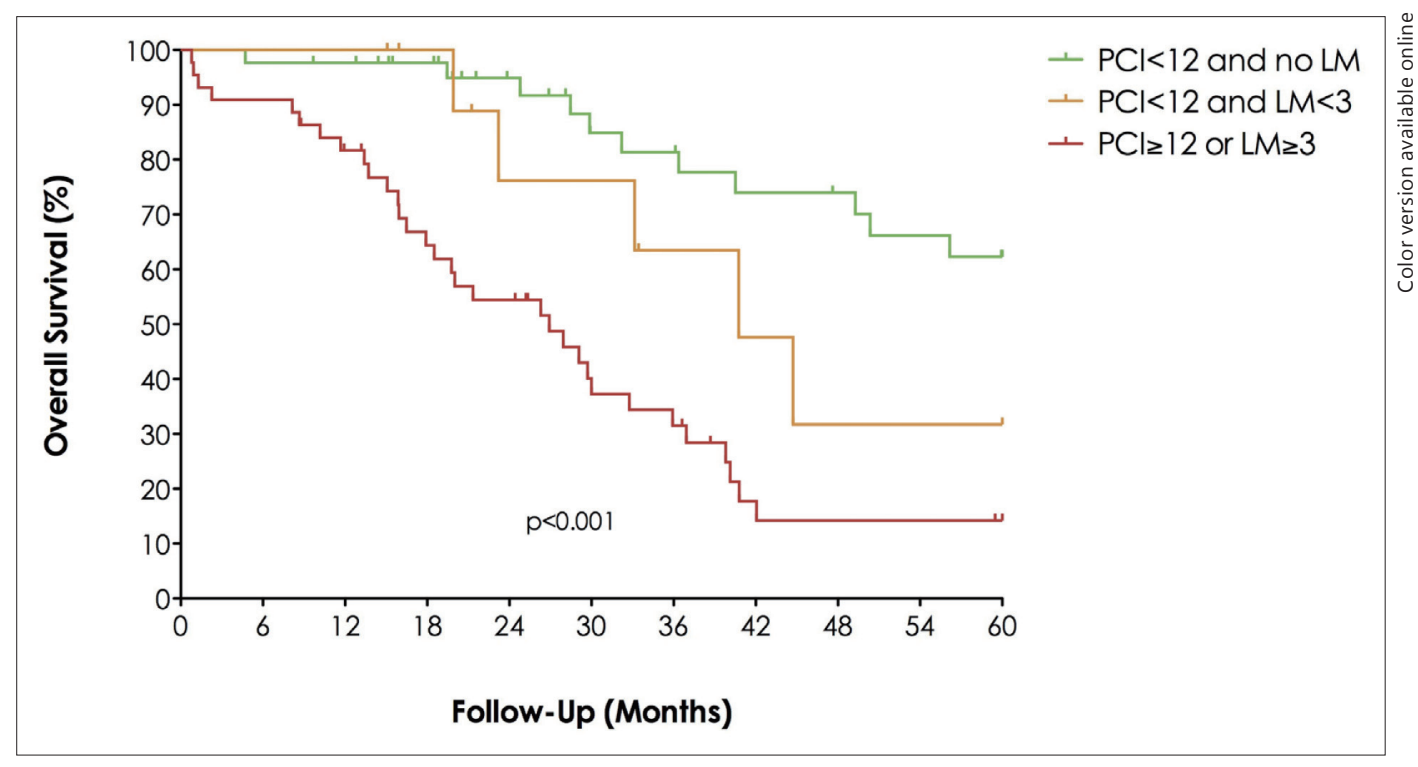

Fig. 1. Overall survival according to number of CLM and the PCI after surgical treatment with curative intent.

tive chemotherapy. Surgical treatment included CRS + HIPEC for all patients associated with liver resection for CLM. Thirty-seven patients who underwent surgery for PC with CLM were matched with 61 patients who underwent surgery for isolated PC. After a mean follow-up of 36 months, 3-year overall and disease-free survival rates were significantly lower in patients with PC and CLM than in patients with isolated PC (40\% vs. $66 \%, \mathrm{p}=0.04$, and $6 \%$ vs. $27 \%$, $\mathrm{p}=0.001$, respectively). By using Cox regression analysis, independent predictive factors of poor overall survival were found to be a $\mathrm{PCI} \geq 12$ (odds-ratio $[\mathrm{OR}]=4.6$ ), a $\mathrm{pN}+$ status $(\mathrm{OR}=3.3$ ), no adjuvant chemotherapy (OR=3.0), and the presence of synchronous CLM (OR=2.0). Median survival was 76 months for patients with PCI $<12$ and no CLM, but only 40 months for patients with one or two CLM ( $p=0.043$ ). If PCI was $\geq 12$ or if the number of CLM was $\geq 3$, the median survival dropped to 27 months (fig. 1). According to these data, the authors concluded that the presence of synchronous CLM predicts poor overall and disease-free survival for patients with PC of colorectal origin. However, for highly selected patients with limited peritoneal (PCI $<12$ ) and hepatic (CLM number $<3$ ) disease, aggressive surgical management is associated with a prolonged overall survival, even if cure is unlikely in most patients.

\section{Radioembolization}

Radioembolization is a radiological interventional procedure that treats liver tumors (both primary tumors and metastases) by delivering high radiation doses focally to the liver lesion while sparing the normal liver parenchyma. To perform selective irradiation of tumors, a particular $\beta$-emitter with limited penetration of tissue (yttrium 90) is loaded onto small dedicated microspheres that are injected into the liver through the hepatic artery. The loaded microspheres lodge preferentially in the microvasculature within the tumor, which is mainly fed by arterial blood flow, whereas liver parenchyma derives $70-80 \%$ of its blood flow from the portal vein. Thus, with this technique it is possible to concentrate an elevated dose focally into the tumor up to 10 times higher than the dose of the surrounding normal 

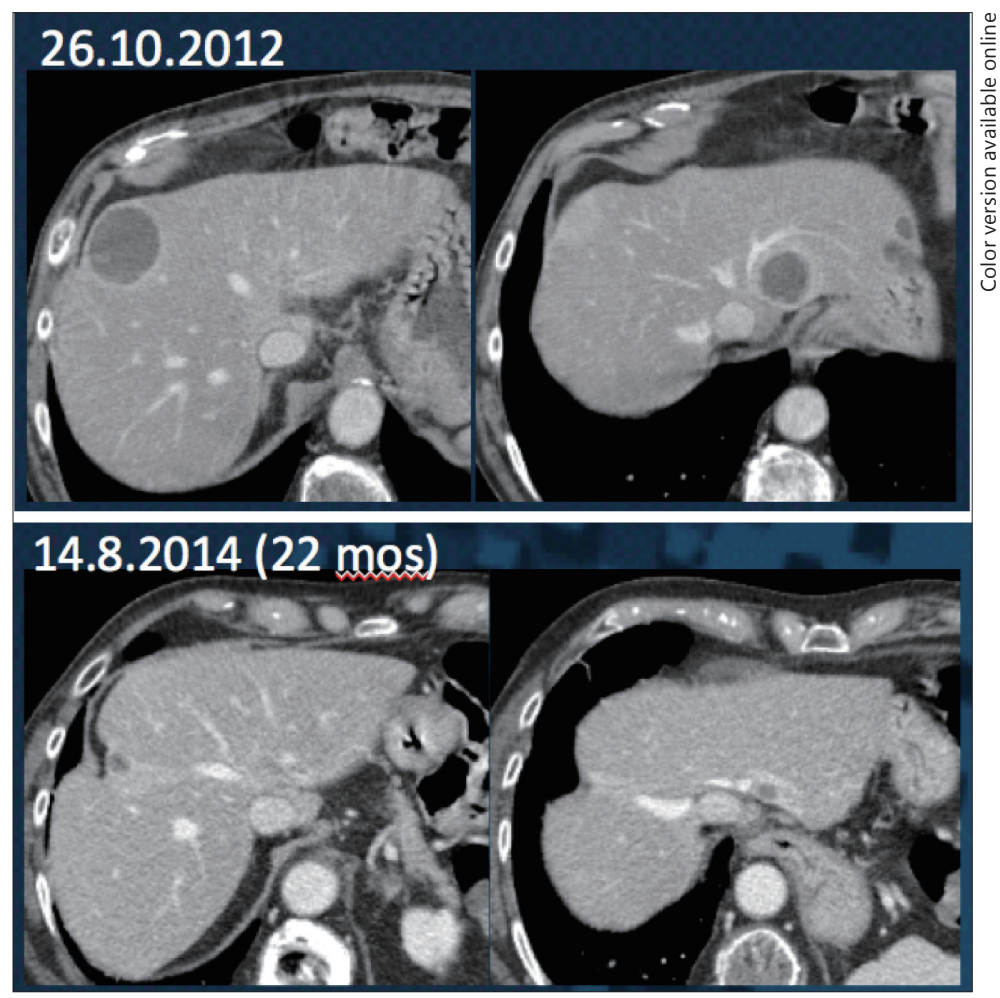

Fig. 2. Super-selective intra-arterial delivery of Y90 Sir-Spheres was performed in a 68-year-old woman with two liver metastases. Approximately 2 years later, computed tomography (CT) showed that the two lesions had virtually disappeared.

liver parenchyma. To successfully execute radioembolization, the following procedures are strictly required: a multidisciplinary team approach, an accurate pretreatment assessment, and complete simulation of the procedure. To avoid damage to non-target organs, collateral vessels have to be embolized before the procedure, and simulation of the embolization with a non-cytotoxic radioactive agent must be performed. Then, the volume and dose of the injection have to be planned and the treatment approach (whole liver, segmental, or selective) has to be chosen (fig. 2).

Radioembolization reportedly increases overall survival in comparison to standard care in patients with unresectable chemorefractory CLM. The role of radioembolization in association with the standard chemotherapy regimen as first line treatment is under evaluation $[20,21]$. In the SIRFLOX trial, patients with liver-dominant or liver-only metastatic colorectal cancer were randomly assigned to receive oxaliplatin-based chemotherapy ( \pm bevacizumab) with or without radioembolization [22]. The addition of radioembolization was associated with a significantly delayed disease progression in the liver ( 20.5 vs. 12.6 months, $p=0.002$ ), but not with an improvement of progression-free survival at any site. Technical advancements, such as superselective radioembolization, have been proposed as a way to overcome some remaining technical limitations of the treatment. In conclusion, even if there is still a lack in knowledge on the topic, radioembolization represents a promising novel treatment option to be considered in the multidisciplinary management of CLM. 


\section{LT for Colorectal Metastases: Myth or Reality?}

The success of LT in the treatment of primary liver tumors has led to renewed interest in its role as a treatment for secondary liver tumors [23]. Standard treatment for CLM includes a combination of chemotherapy and liver resection. Liver resectability has increased thanks to progresses in chemotherapy and parenchyma-sparing and/or staged procedures, but curative liver resection is currently applicable in only $15-20 \%$ of patients. Total hepatectomy followed by transplantation for liver-only metastatic disease is a potentially curative therapeutic option. Successful hepatic resection may result in 5-year overall survival rates of $30-40 \%$. In a Norwegian pilot study, LT for CLM obtained 1-, 3- and 5-year overall survival rates of $96 \%, 70 \%$, and $60 \%$, respectively [24]. Parameters found to be favorable for survival were: diameter of the largest CLM $<55 \mathrm{~mm}$, interval $>2$ years between colorectal and transplant operations, pre-LT carcinoembryonic antigen level $<80 \mathrm{ng} / \mathrm{ml}$, and responsive or stable disease under chemotherapy. With aggressive surgical treatment of recurrences, 8 of 21 patients were alive 4-8 years after LT and all four with metachronous CLM were alive 5-8 years after transplantation. These results are superior to those obtained with conventional treatment in similar patients. The retrospective analysis of pulmonary micronodules at the time of LT showed that these lesions were in fact metastases. The results of this pilot LT study should be interpreted with caution because of the small number of patients, the absence of a control group, and the high rate of relapse with pulmonary metastases.

It is obvious that the limited availability of liver allografts needs careful consideration, especially when compared with the large number of patients with unresectable liver-only colorectal metastases. Using a donor liver in patients with CLM cannot be viewed as unethical nor as a waste of a valuable resource in the light of current evidence. It is important to remember in this context that up to $10 \%$ of all LTs are repeat transplants, after which 5-year overall survival reaches around 50\%, a figure that seems achievable with LT in selected patients with CLM. However, the present applicability of LT for CLM is very limited, and the future applicability of LT for CLM remains to be elucidated.

LT techniques, such as the "rapid concept" combining two-stage hepatectomy, right portal vein transection, and regeneration of an auxiliary left lobe liver graft (segments 2 and 3), must be explored. This approach may be applied in split-liver (one donor liver for two recipients) or reduced-risk living-donor LT procedures. Taking recent progress in both medical and surgical liver oncology into account, the time has come for oncologists and liver surgeons to consider LT in the therapeutic algorithm of CLM.

\section{Radiotherapy}

SBRT has developed as a system for delivering a conformal high dose of radiation in a small number of fractions, and it has been used as an effective and safe ablative local therapy in cases of inoperable CLM. Most published studies enrolled patients with a good performance status, absent or stable extrahepatic disease, and fewer than five lesions with a maximum tumor size of $6 \mathrm{~cm}$ [25-28]. Radiation doses range from 22 to $75 \mathrm{~Gy}$ in one to six fractions. Local control (LC) rates of $67-100 \%$ at 1 year and $55-90 \%$ at 2 years have been achieved [25-28]. In most trials, LC was associated with lesion size and with higher prescription doses [26]. In a phase II study, Scorsetti et al. used an ablative prescription dose of 75 Gy in three fractions and revealed no significantly increased risk of local recurrence for lesions $>3 \mathrm{~cm}$ [25] (fig. 3). Median overall survival after SBRT ranges from 10 to 34 months and is associated with lesion size, metachronous presentation, and LC, as demonstrated by Hoyer et al. and Chang 


\section{Liver

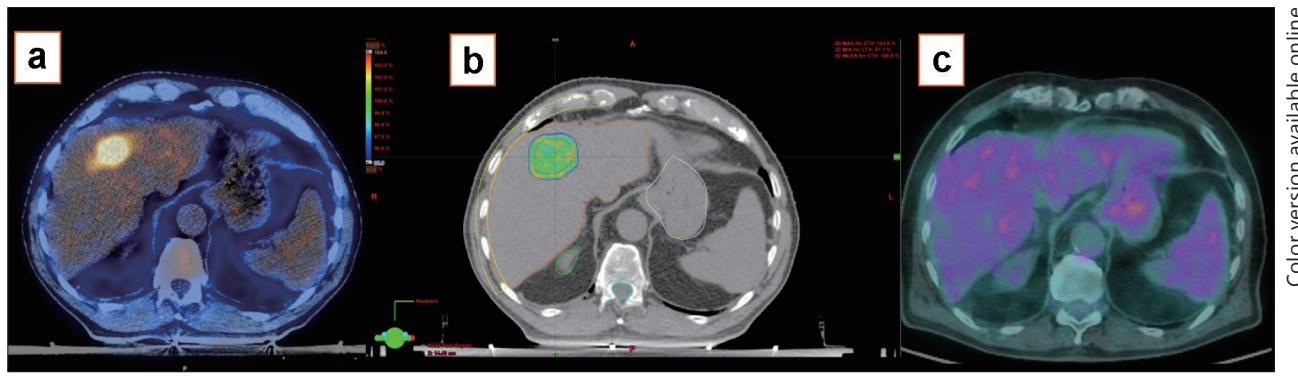

Fig. 3. Patient treated with SBRT for inoperable CLM. a Pre-treatment positron emission tomography (PET) image showing the lesions. b Visualization of dose distribution on the planning target volume. c PET-CT image at 6 months after SBRT showing complete metabolic response.

Table 1. Results of the most relevant studies on SBRT for CLM

\begin{tabular}{|c|c|c|c|c|c|c|c|c|}
\hline \multirow[t]{2}{*}{$\begin{array}{l}\text { Author } \\
\text { Study design }\end{array}$} & \multirow[t]{2}{*}{$\begin{array}{c}\text { No. of } \\
\text { patients } \\
\text { with CLM }\end{array}$} & \multirow[t]{2}{*}{$\begin{array}{l}\text { No. of } \\
\text { CLM }\end{array}$} & \multirow[t]{2}{*}{$\begin{array}{l}\text { Dose } \\
\text { (Gy/fr) }\end{array}$} & \multirow[t]{2}{*}{$\begin{array}{l}\text { Follow-up } \\
\text { (median) }\end{array}$} & \multicolumn{2}{|c|}{$\begin{array}{c}\text { Actuarial LC } \\
(\%)\end{array}$} & \multicolumn{2}{|c|}{$\begin{array}{l}\text { Actuarial overall } \\
\text { survival } \\
(\%)\end{array}$} \\
\hline & & & & & 1 year & 2 years & 1 year & 2 years \\
\hline $\begin{array}{l}\text { Scorsetti [25] } \\
\text { Phase II }\end{array}$ & 42 & 52 & $75 \mathrm{~Gy} / 3 \mathrm{fr}$ & 18 months & $95 \%$ & $91 \%$ & $80 \%$ & $70 \%$ \\
\hline $\begin{array}{l}\text { Chang [26] } \\
\text { Phase II }\end{array}$ & 65 & 102 & $\begin{array}{c}22-60 \\
\mathrm{~Gy} / 1-6 \mathrm{fr}\end{array}$ & 1.2 years & $67 \%$ & $55 \%$ & $72 \%$ & $38 \%$ \\
\hline $\begin{array}{l}\text { Hoyer [27] } \\
\text { Phase II }\end{array}$ & 44 & - & $45 \mathrm{~Gy} / 3 \mathrm{fr}$ & 4.3 years & $90 \%$ & $78 \%$ & $67 \%$ & $38 \%$ \\
\hline $\begin{array}{l}\text { Van der Pool[28] } \\
\text { Phase I-II }\end{array}$ & 20 & 31 & $\begin{array}{c}37.5 \mathrm{~Gy} / 3 \mathrm{fr} \\
45 \mathrm{~Gy} / 3 \mathrm{fr}\end{array}$ & 26 months & $100 \%$ & $74 \%$ & $100 \%$ & $83 \%$ \\
\hline
\end{tabular}

fr=fraction.

et al. $[27,28]$. The toxicity profile of SBRT in these series was excellent, with an incidence of radiation-induced liver disease of less than $1 \%$ [25-28]. The most relevant prospective SBRT series for CLM are summarized in table 1.

Currently, the selection criteria for patients with CLM who are candidates for SBRT are controversial, and a multidisciplinary board discussion is recommended. According to the current literature, liver SBRT is indicated in inoperable patients with a good performance status, number of hepatic lesions $\leq 3$, size of lesions $\leq 3 \mathrm{~cm}$, lesion distance from organs at risk $>8 \mathrm{~mm}$, adequate liver function, and a healthy liver volume $>1000 \mathrm{~cm}^{3}$ [29]. A total dose of $60 \mathrm{~Gy}$ in three fractions is recommended for lesions with a diameter $\leq 3 \mathrm{~cm}$, whereas for lesions $>3 \mathrm{~cm}$, a higher prescription dose is necessary to obtain the same rate of LC [29]. In conclusion, SBRT is a safe, non-invasive, and effective therapeutic option for patients with inoperable CLM. To evaluate the real impact of SBRT on survival for these oligometastatic patients, the selection of patients with a favorable prognosis, comparative randomized clinical trials with other local treatments, and analysis of the associations with chemotherapy and targeted therapy are required. 


\section{Interstitial Treatments: What's New about Radiofrequency and Microwave Ablation?}

Radiofrequency ablation (RFA) has been used for more than 20 years for the local treatment of CLM. Accepted applications include patients inoperable because of disease extent/ distribution, local progression after resection, patients without an adequate liver reserve, or patients with co-morbidities. RFA can also be used as part of a test-of-time approach. Finally, it can be indicated as a result of patient choice. Future applications may include resectable disease, e.g., for small solitary tumors.

Given that optimal ablation requires at minimum a 1-cm ablative margin (the "safety margin"), the tumor size, number, and location are fundamental parameters to be taken into account before enrolling patients for ablation. Additional factors to be considered are the ablation technology to be employed, the imaging guidance, and intra-procedural imaging assessment. Analysis of local recurrence rates and survival shows a significant advantage for small tumors, with the most common cut-off point being $3 \mathrm{~cm}$.

In recent years, studies reporting data on LC and survival rates in large case series with long-term follow-up and the introduction of new ablative methods (microwave ablation [MWA] and irreversible electroporation) have been the major advancements in ablation of hepatic CLM.

In a recent position paper [30], an international group of experts reviewed the results of RFA for CLM in 15 research articles that included a total patient population of 1613 . They showed a wide variability of LC (55-97\%) and 5-year survival rates (17-51\%), but they also observed a dramatic increase in the mean 5 -year survival rate $(50 \%)$ when ablation was applied to patients with potentially resectable disease. Tumor size and location and, consequently, the thickness of the ablative margin were the major determinants of LC rates. Based on this analysis, the group of experts produced the first published "recommendations" for ablation of CLM.

In the most recently published series, thanks to more accurate selection of lesions to be ablated and thicker periablative margins, both LC rates for metastases less than $3 \mathrm{~cm}$ in diameter and overall survival rates of patients have significantly increased, with rates approaching those of the best series reported for surgical interventions [31-34].

With the introduction to clinical practice of high-power MWA, a significant improvement in LC of ablated metastases larger than $2-3 \mathrm{~cm}$ is expected because of the potential for MWA to achieve larger and more rounded volumes of necrosis with a shorter exposure time, together with a minimization of the heat-sink effect of RFA $[35,36]$. In addition, with the new IRE technique, it will likely be possible to safely ablate CLM in locations too dangerous for RFA and MWA, e.g., adjacent to bile ducts, gallbladder, duodenum, and colon, as has been initially reported in very recent papers [37].

\section{Conclusions}

The management of metastatic colorectal cancer is becoming more aggressive and more multidisciplinary. In addition to standard approaches (resection of liver metastases and chemotherapy), new options have to be considered. Selected patients with limited synchronous peritoneal and liver disease can be scheduled for surgery with a survival benefit. LT has reinstated the possibility of surgery for some unresectable patients and, even if indications remain to be standardized, preliminary outcomes are extremely promising. Radioembolization is an additional tool for the treatment of unresectable patients, and research is under way to 
investigate its potential role with chemotherapy in resectable tumors. SBRT is a safe, noninvasive, and effective therapeutic option for patients with inoperable oligometastatic CLM. Finally, interstitial treatments for CLM have become more effective, with results approaching those of surgical series.

\section{Conflicts of Interest}

The authors declare that no conflicts of interest exist.

\section{References}

1 Charnsangavej C, Clary B, Fong Y, Grothey A, Pawlik TM, Choti MA: Selection of patients for resection of hepatic colorectal metastases: expert consensus statement. Ann Surg Oncol 2006;13:1261-1268.

2 Minagawa M, Makuuchi M, Torzilli G, Takayama T, Kawasaki S, Kosuge T, Yamamoto J, Imamura H: Extension of the frontiers of surgical indications in the treatment of liver metastases from colorectal cancer: long-term results. Ann Surg 2000;231:487-499.

3 Adam R, De Gramont A, Figueras J, Guthrie A, Kokudo N, Kunstlinger F, Loyer E, Poston G, Rougier P, Rubbia-Brandt L, Sobrero A, Tabernero J, Teh C, Van Cutsem E, Jean-Nicolas Vauthey of the EGOSLIM (Expert Group on OncoSurgery management of LIver Metastases) group: The oncosurgery approach to managing liver metastases from colorectal cancer: a multidisciplinary international consensus. Oncologist 2012;17:1225-1239.

4 Khatri VP, Petrelli NJ, Belghiti J: Extending the frontiers of surgical therapy for hepatic colorectal metastases: is there a limit? J Clin Oncol 2005;23:8490-8499.

5 Viganò L, Capussotti L, Majno P, Toso C, Ferrero A, De Rosa G, Rubbia-Brandt L, Mentha G: Liver resection in patients with eight or more colorectal liver metastases. Br J Surg 2015;102:92-101.

6 Wicherts DA, Miller R, de Haas RJ, Bitsakou G, Vibert E, Veilhan LA, Azoulay D, Bismuth H, Castaing D, Adam R: Long-term results of two-stage hepatectomy for irresectable colorectal cancer liver metastases. Ann Surg 2008;248:994-1005.

7 Leung U, Gönen M, Allen PJ, Kingham TP, DeMatteo RP, Jarnagin WR, D’Angelica MI: Colorectal cancer liver metastases and concurrent extrahepatic disease treated with resection. Ann Surg 2016; (In press).

8 Elias D, Ouellet JF, Bellon N, Pignon JP, Pocard M, Lasser P: Extrahepatic disease does not contraindicate hepatectomy for colorectal liver metastases. Br J Surg 2003;90:567-574.

9 de Haas RJ, Wicherts DA, Andreani P, Pascal G, Saliba F, Ichai P, Adam R, Castaing D, Azoulay D: Impact of expanding criteria for resectability of colorectal metastases on short- and long-term outcomes after hepatic resection. Ann Surg 2011;253:1069-1079.

10 Viganò L, Russolillo N, Ferrero A, Langella S, Sperti E, Capussotti L: Evolution of long-term outcome of liver resection for colorectal metastases: analysis of actual 5-year survival rates over two decades. Ann Surg Oncol 2012;19:2035-2044.

11 House MG, Ito H, Gönen M, Fong Y, Allen PJ, DeMatteo RP, Brennan MF, Blumgart LH, Jarnagin WR, D'Angelica MI: Survival after hepatic resection for metastatic colorectal cancer: trends in outcomes for 1,600 patients during two decades at a single institution. J Am Coll Surg 2010;210:744-752, 752-755.

12 Viganò L, Ferrero A, Lo Tesoriere R, Capussotti L: Liver surgery for colorectal metastases: results after 10 years of follow-up. Long-term survivors, late recurrences, and prognostic role of morbidity. Ann Surg Oncol 2008;15:2458-2464.

13 Kopetz S, Chang GJ, Overman MJ, Eng C, Sargent DJ, Larson DW, Grothey A, Vauthey JN, Nagorney DM, McWilliams RR: Improved survival in metastatic colorectal cancer is associated with adoption of hepatic resection and improved chemotherapy. J Clin Oncol 2009;27:3677-3683.

14 Loupakis F, Cremolini C, Masi G, Lonardi S, Zagonel V, Salvatore L, Cortesi E, Tomasello G, Ronzoni M, Spadi R, Zaniboni A, Tonini G, Buonadonna A, Amoroso D, Chiara S, Carlomagno C, Boni C, Allegrini G, Boni L, Falcone A: Initial therapy with FOLFOXIRI and bevacizumab for metastatic colorectal cancer. N Engl J Med 2014;371:1609-1618.

15 Van Cutsem E, Köhne CH, Hitre E, Zaluski J, Chang Chien CR, Makhson A, D’Haens G, Pintér T, Lim R, Bodoky G, Roh JK, Folprecht G, Ruff P, Stroh C, Tejpar S, Schlichting M, Nippgen J, Rougier P: Cetuximab and chemotherapy as initial treatment for metastatic colorectal cancer. N Engl J Med 2009;360:1408-1417.

16 Elias D, Lefevre JH, Chevalier J, Brouquet A, Marchal F, Classe JM, Ferron G, Guilloit JM, Meeus P, Goéré D, Bonastre J: Complete cytoreductive surgery plus intraperitoneal chemohyperthermia with oxaliplatin for peritoneal carcinomatosis of colorectal origin. J Clin Oncol 2009;27:681-685.

17 Elias D, Gilly F, Boutitie F, Quenet F, Bereder JM, Mansvelt B, Lorimier G, Dubè P, Glehen O: Peritoneal colorectal carcinomatosis treated with surgery and perioperative intraperitoneal chemotherapy: retrospective analysis of 523 patients from a multicentric French study. J Clin Oncol 2010;28:63-68. 
18 Elias D, Faron M, Iuga BS, Honoré C, Dumont F, Bourgain JL, Dartigues P, Ducreux M, Goéré D: Prognostic similarities and differences in optimally resected liver metastases and peritoneal metastases from colorectal cancers. Ann Surg 2015;261:157-163.

19 Maggiori L, Goéré D, Viana B, Tzanis D, Dumont F, Honoré C, Eveno C, Elias D: Should patients with peritoneal carcinomatosis of colorectal origin with synchronous liver metastases be treated with a curative intent? A case-control study. Ann Surg 2013;258:116-121.

20 Habito CM: Editorial: Radioembolization in the treatment of liver cancer: a multidisciplinary approach for individualized therapy. Front Oncol 2015;5:216.

21 Cremonesi M, Chiesa C, Strigari L, Ferrari M, Botta F, Guerriero F, De Cicco C, Bonomo G, Orsi F, Bodei L, Di Dia A, Grana CM, Orecchia R: Radioembolization of hepatic lesions from a radiobiology and dosimetric perspective. Front Oncol 2014;4:210.

22 van Hazel GA, Heinemann V, Sharma NK, Findlay MP, Ricke J, Peeters M, Perez D, Robinson BA, Strickland AH, Ferguson T, Rodríguez J, Kröning H, Wolf I, Ganju V, Walpole E, Boucher E, Tichler T, Shacham-Shmueli E, Powell A, Eliadis P, Isaacs R, Price D, Moeslein F, Taieb J, Bower G, Gebski V, Van Buskirk M, Cade DN, Thurston K, Gibbs P: SIRFLOX: Randomized Phase III Trial Comparing First-Line mFOLFOX6 (Plus or Minus Bevacizumab) Versus mFoLFOX6 (Plus or Minus Bevacizumab) Plus Selective Internal Radiation Therapy in Patients With Metastatic Colorectal Cancer. J Clin Oncol 2016;34:1723-1731.

23 Foss A, Lerut JP: Liver transplantation for metastatic liver malignancies. Curr Opin Organ Transplant 2014;19:235-244.

24 Hagness M, Foss A, Line PD, Scholz T, Jørgensen PF, Fosby B, Boberg KM, Mathisen O, Gladhaug IP, Egge TS, Solberg S, Hausken J, Dueland S: Liver transplantation for nonresectable liver metastases from colorectal cancer. Ann Surg 2013;257:800-806.

25 Scorsetti M, Comito T, Tozzi A, Navarria P, Fogliata A, Clerici E, Mancosu P, Reggiori G, Rimassa L, Torzilli G, Tomatis S, Santoro A, Cozzi L: Final results of a phase II trial for stereotactic body radiation therapy for patients with inoperable liver metastases from colorectal cancer. I Cancer Res Clin Oncol 2015;141:543-553.

26 Chang DT, Swaminath A, Kozak M, Weintraub J, Koong AC, Kim J, Dinniwell R, Brierley J, Kavanagh BD, Dawson LA, Schefter TE: Stereotactic body radiotherapy for colorectal liver metastases: a pooled analysis. Cancer 2011;117:4060-4069.

27 Hoyer M, Roed H, Traberg Hansen A, Ohlhuis L, Petersen J, Nellemann H, Kiil Berthelsen A, Grau C, Aage Engelholm S, Von der Maase H: Phase II study on stereotactic body radiotherapy of colorectal metastases. Acta Oncol 2006;45:823-830.

28 van der Pool AE, Méndez Romero A, Wunderink W, Heijmen BJ, Levendag PC, Verhoef C, Ijzermans JN: Stereotactic body radiation therapy for colorectal liver metastases. Br J Surg 2010;97:377-382.

29 Scorsetti M, Clerici E, Comito T: Stereotactic body radiation therapy for liver metastases. J Gastrointest Oncol 2014;5:190-197.

30 Gillams A, Goldberg N, Ahmed M, Bale R, Breen D, Callstrom M, Chen MH, Choi BI, de Baere T, Dupuy D, Gangi A, Gervais D, Helmberger T, Jung EM, Lee F, Lencioni R, Liang P, Livraghi T, Lu D, Meloni F, Pereira P, Piscaglia F, Rhim H, Salem R, Sofocleous C, Solomon SB, Soulen M, Tanaka M, Vogl T, Wood B, Solbiati L: Thermal ablation of colorectal liver metastases: a position paper by an international panel of ablation experts, The Interventional Oncology Sans Frontières meeting 2013. Eur Radiol 2015;25:3438-3454.

31 Babawale SN, Jensen TM, Frøkjær JB: Long-term survival following radiofrequency ablation of colorectal liver metastases: A retrospective study. World J Gastrointest Surg 2015;7:33-38.

32 Kim KH, Yoon YS, Yu CS, Kim TW, Kim HJ, Kim PN, Ha HK, Kim JC: Comparative analysis of radiofrequency ablation and surgical resection for colorectal liver metastases. J Korean Surg Soc 2011;81:25-34.

33 Shady W, Petre EN, Gonen M, Erinjeri JP, Brown KT, Covey AM, Alago W, Durack JC, Maybody M, Brody LA, Siegelbaum RH, D’Angelica MI, Jarnagin WR, Solomon SB, Kemeny NE, Sofocleous CT: Percutaneous radiofrequency ablation of colorectal cancer liver metastases: factors affecting outcomes-a 10-year experience at a single center. Radiology 2016;278:601-611.

34 Solbiati L, Ahmed M, Cova L, Ierace T, Brioschi M, Goldberg SN: Small liver colorectal metastases treated with percutaneous radiofrequency ablation: local response rate and long-term survival with up to 10-year follow-up. Radiology 2012;265:958-968.

35 Eng OS, Tsang AT, Moore D, Chen C, Narayanan S, Gannon CJ, August DA, Carpizo DR, Melstrom LG: Outcomes of microwave ablation for colorectal cancer liver metastases: a single center experience. J Surg Oncol 2015;111:410-413.

36 Wang J, Liang P, Yu J, Yu MA, Liu F, Cheng Z, Yu X: Clinical outcome of ultrasound-guided percutaneous microwave ablation on colorectal liver metastases. Oncol Lett 2014;8:323-326.

37 Scheffer HJ, Melenhorst MC, Echenique AM, Nielsen K, van Tilborg AA, van den Bos W, Vroomen LG, van den Tol PM, Meijerink MR: Irreversible electroporation for colorectal liver metastases. Tech Vasc Interv Radiol 2015;18:159-169. 